\title{
Relationship Between Brachial Arterial Endothelial Function and Lumbar Spine Bone Mineral Density in Postmenopausal Women
}

\author{
Hiroyuki Sumino, MD; Shuichi Ichikawa, MD*; Shu Kasama, MD*; \\ Takashi Takahashi, MD**; Hironosuke Sakamoto, MD; Hisao Kumakura, MD*; \\ Yoshiaki Takayama, MD*; Tsugiyasu Kanda, MD**; \\ Masami Murakami, MD ${ }^{\dagger}$; Masahiko Kurabayashi, MD
}

\begin{abstract}
Background Osteoporosis and endothelial dysfunction have been associated with atherosclerosis. The correlation between brachial arterial endothelial function and lumbar spine bone mineral density (BMD) in postmenopausal women will be investigated.

Methods and Results The endothelial function in 85 postmenopausal women, including 28 women with normal spinal BMD, 27 women with osteopenia, and 30 women with osteoporosis were studied. Brachial arterial flow-mediated vasodilatation (FMD) after reactive hyperemia was assessed by ultrasonography. The BMD at the lumbar spine (lumbar 2 to 4 vertebrae) was measured by dual-energy X-ray absorptiometry. Age, years since menopause, and FMD were significantly greater in the osteoporosis group than in the normal BMD group ( $\mathrm{p}<$ $0.01, \mathrm{p}<0.05$, and $\mathrm{p}<0.05$, respectively). The BMD was significantly lower in the osteoporosis group than in the osteoporosis or normal BMD group (both $\mathrm{p}<0.01$ ). After adjusting for age and years since menopause, women with osteoporosis had significantly lesser FMD than those with normal BMD $(\mathrm{p}<0.05)$. The univariate linear regression analysis revealed that brachial arterial FMD was significantly positively correlated with BMD $(\mathrm{r}=0.31, \mathrm{p}<0.01)$, but showed no significant association with other clinical variables. In multivariate regression analysis, the FMD was significantly positively correlated with BMD $(\mathrm{p}<0.01)$, but not with other variables.

Conclusions Postmenopausal women with osteoporosis might have impaired brachial arterial endothelial function, suggesting that brachial artery endothelial function might be associated with lumbar spine bone mass in postmenopausal women. (Circ J 2007; 71: 1555-1559)
\end{abstract}

Key Words: Bone mass; Endothelial function; Menopause; Women

C ardiovascular disease and osteoporosis are known to be major causes of morbidity and mortality in postmenopausal women!,2 In recent years, several studies have examined the association between atherosclerosis at different sites and osteoporosis or low bone mineral density (BMD) in women, and suggested that the development of osteoporosis is a risk for advanced atherosclerosis after menopause ${ }^{3-7}$ Endothelial dysfunction is thought to represent one of the initial stages in the development of atherosclerosis. The endothelium plays a major role in determining the vascular tone by producing and releasing vasodilators, such as nitric oxide (NO), which helps in preventing atherosclerosis by maintaining vasodilatation and inhibiting platelet aggregation, leukocyte adhesion, and

(Received April 3, 2007; revised manuscript received May 30, 2007; accepted June 12, 2007)

Department of Nursing, Faculty of Nursing, Takasaki University of Health and Welfare, Takasaki, *Internal Medicine, Cardiovascular Hospital of Central Japan, Shibukawa, **Department of General Medicine, Kanazawa Medical University, Uchinada, ${ }^{\text {Department of }}$ Clinical Laboratory Medicine and Department of Medicine and Biological Science, Gunma University Graduate School of Medicine, Maebashi, Japan

Mailing address: Hiroyuki Sumino, MD, Department of Nursing, Faculty of Nursing, Takasaki University of Health and Welfare, 501 Nakaorui-machi, Takasaki 370-0033, Japan. E-mail: hsumino@ takasaki-u.ac.jp proliferation of the vascular smooth muscle cells, 8 ,9 A recent study reported that postmenopausal women with osteoporosis have a lower endothelial function than those with normal BMD5 However, the relationship between brachial arterial endothelial function and lumbar spine BMD in postmenopausal women remains unknown.

We compared the brachial arterial endothelial function among postmenopausal women with normal lumbar spine $\mathrm{BMD}$, osteopenia, and osteoporosis. In addition, we evaluated the correlation between brachial arterial endothelial function and lumbar spine BMD in postmenopausal women.

\section{Methods}

\section{Subjects}

Of 322 consecutive Japanese postmenopausal women who came our clinic to assess the presence of osteoporosis, 85 subjects (mean age: $57.9 \pm 8.3$ years; range: $45 \pm 75$ years) participated in this study. At least 1 year had passed since the last menstrual period in each of the subjects. The menopausal status was confirmed by a serum estradiol concentration of $<20 \mathrm{pg} / \mathrm{ml}$ and a serum follicle-stimulating hormone (FSH) concentration of $>40 \mathrm{mIU} / \mathrm{ml}$. Patients with a history of tobacco, alcohol or caffeine use, fractures, diabetes mellitus, hypertension, myocardial infarction, liver disorders, or a family history of osteoporotic fractures or premature myocardial infarction were excluded from the study. None 
Table 1 Clinical and Laboratory Characteristics of the Normal BMD, Osteopenia, and Osteoporosis Groups

\begin{tabular}{|c|c|c|c|}
\hline & Normal BMD & Osteopenia & Osteoporosis \\
\hline No. & 28 & 27 & 30 \\
\hline Age (years) & $54.4 \pm 7.1$ & $55.6 \pm 6.9$ & $63.2 \pm 7.8 * *, \dagger$ \\
\hline Years since menopause (years) & $4.8 \pm 6.9$ & $5.4 \pm 6.0$ & $13.2 \pm 7.7 * *$ \\
\hline Body mass index $\left(\mathrm{kg} / \mathrm{m}^{2}\right)$ & $22.6 \pm 2.7$ & $22.3 \pm 2.1$ & $21.5 \pm 3.8$ \\
\hline Follicle-stimulating hormone $(\mathrm{mIU} / \mathrm{ml})$ & $65.5 \pm 14.3$ & $64.4 \pm 11.4$ & $65.7 \pm 19.2$ \\
\hline Estradiol $(\mathrm{pg} / \mathrm{ml})$ & $12.3 \pm 2.1$ & $11.3 \pm 2.6$ & $12.0 \pm 2.9$ \\
\hline Systolic blood pressure $(\mathrm{mmHg})$ & $121.6 \pm 14.0$ & $122.2 \pm 16.9$ & $123.3 \pm 13.3$ \\
\hline Diastolic blood pressure ( $\mathrm{mmHg}$ ) & $76.9 \pm 7.4$ & $75.8 \pm 10.0$ & $75.5 \pm 8.1$ \\
\hline Heart rate (beats/min) & $64.4 \pm 5.2$ & $65.3 \pm 4.4$ & $65.5 \pm 5.8$ \\
\hline Total cholesterol $(\mathrm{mg} / \mathrm{dl})$ & $206.8 \pm 28.8$ & $211.6 \pm 33.2$ & $204.8 \pm 32.3$ \\
\hline HDL-cholesterol ( $\mathrm{mg} / \mathrm{dl})$ & $60.1 \pm 12.4$ & $57.0 \pm 12.0$ & $58.8 \pm 13.0$ \\
\hline Triglyceride $(\mathrm{mg} / \mathrm{dl})$ & $93.3 \pm 43.1$ & $105.3 \pm 48.0$ & $88.5 \pm 41.1$ \\
\hline LDL-cholesterol $(\mathrm{mg} / \mathrm{dl})$ & $128.0 \pm 26.0$ & $133.6 \pm 33.3$ & $128.3 \pm 28.0$ \\
\hline Fasting plasma glucose $(\mathrm{mg} / \mathrm{dl})$ & $103.2 \pm 16.1$ & $96.5 \pm 10.1$ & $96.8 \pm 6.9$ \\
\hline Creatinine $(\mathrm{mg} / \mathrm{dl})$ & $0.68 \pm 0.10$ & $0.65 \pm 0.09$ & $0.66 \pm 0.10$ \\
\hline Calcium $(\mathrm{mg} / \mathrm{dl})$ & $9.1 \pm 0.4$ & $9.2 \pm 0.3$ & $9.2 \pm 0.4$ \\
\hline Phosphatus (mg/dl) & $3.6 \pm 0.4$ & $3.4 \pm 0.3$ & $3.6 \pm 0.4$ \\
\hline Osteocalcin $(\mathrm{ng} / \mathrm{ml})$ & $7.7 \pm 2.4$ & $8.0 \pm 2.0$ & $9.6 \pm 2.7 *$ \\
\hline Basal arterial diameter ( $\mathrm{mm})$ & $4.0 \pm 0.5$ & $4.1 \pm 0.6$ & $4.0 \pm 0.6$ \\
\hline Basal blood flow $(\mathrm{ml} / \mathrm{min})$ & $187 \pm 78$ & $168 \pm 52$ & $183 \pm 89$ \\
\hline Hyperemic blood flow (\%) & $749 \pm 777$ & $631 \pm 718$ & $451 \pm 800$ \\
\hline Flow-mediated vasodilatation (\%) & $9.4 \pm 5.7$ & $7.6 \pm 2.8$ & $6.2 \pm 3.8 *$ \\
\hline Nitroglycerin-induced vasodilatation (\%) & $17.3 \pm 8.0$ & $17.1 \pm 9.0$ & $17.4 \pm 16.1$ \\
\hline$B M D\left(\mathrm{~g} / \mathrm{cm}^{2}\right)$ & $1.04 \pm 0.06$ & $0.84 \pm 0.06 * *$ & $0.64 \pm 0.05 * *, \dagger$ \\
\hline
\end{tabular}

$B M D$, bone mineral density; $H D L$, high-density lipoprotein; $L D L$, low-density lipoprotein.

All the results are presented as means $\pm S D$.

${ }^{*} p<0.05,{ }^{*} p<0.01$ vs normal BMD, ${ }^{\dagger} p<0.01$ vs osteopenia.

of the subjects had received hormone replacement therapy or had taken any steroids or medications known to influence lipoprotein metabolism, bone metabolism or blood pressure. Written informed consent was obtained from each of the participants prior to admission into the study, and the study protocol was approved by the Ethics Committee of the Cardiovascular Hospital of Central Japan.

The study subjects were assigned to 1 of 3 groups according to the BMD at the lumbar spine: control group (normal BMD; 28 women), osteopenia group (BMD 1-2.5 SD below the mean value for young adults; 27 women), and osteoporosis group (BMD more than 2.5 SD below the mean value for young adults; 30 women). This classification system, which was based on the BMD, was established by an expert panel from the World Health Organization! ${ }^{10}$

\section{Physical Examination}

The height and weight of the subjects were measured, and the body mass index was calculated. The blood pressure was measured in the morning after the patient had fasted overnight $(12 \mathrm{~h})$. The measurement was obtained by the same investigator with a sphygmomanometer using the right arm of the subject, after she had rested for $10 \mathrm{~min}$ in the supine position.

\section{Measurement of BMD}

The validity of this method has been demonstrated in previous study!1 The BMD was evaluated at the lumbar spine (using the central portion of a lateral scout view of the lumbar 2 to 4 vertebrae) by dual-energy X-ray absorptiometry (DXA; QDR-1000W, Hologic, Waltham, MA, USA), and expressed as grams per square centimeter. The $\mathrm{Z}$-score is the number of standard deviations (SD) by which a given measurement differs from the mean for a sex-, age-, and race-matched reference population. The Tscore is the number of SDs by which a given measurement differs from the mean for a normal young adult reference population. All the measurements were performed by 2 operators, and 1 technician analyzed all of the scans. The inter- and intra-operator coefficients of variation were less than $1 \%$.

\section{Measurement of Brachial Arterial Endothelial Function}

The validity of this method has been demonstrated in previous studies. ${ }^{12-14}$ In brief, after the subjects had rested in the supine position for $10 \mathrm{~min}$, imaging of the right brachial artery and measurement of the vasodilatory responses were conducted using a high-resolution Doppler ultrasonography equipment with a 7.5-MHz transducer (SSH-160A, Toshiba Medical Systems Corporation, Tokyo, Japan). A non-tortuous segment of the brachial artery was scanned longitudinally approximately $4-5 \mathrm{~cm}$ above the elbow, where the clearest images could be obtained. After determining the optimum transducer position, the skin was marked and the arm was kept in the same position throughout the study. After baseline images of the brachial artery were obtained and the arterial flow velocity was determined, a blood pressure cuff tied around the proximal portion of the forearm, distal to the antecubital fossa, was inflated to $250 \mathrm{mmHg}$ for $5 \mathrm{~min}$, followed by quick deflation. Flow velocity in the brachial artery was determined immediately and 1 min after the quick cuff deflation. After allowing a 10 min rest period, a new baseline image was obtained, the patient was given sublingual nitroglycerin $(0.3 \mathrm{mg})$, and the brachial artery imaging was conducted again for the next $4 \mathrm{~min}$. All the scans were recorded on VHS videotape for later analysis, along with blood pressure and heart rate recordings during each stage of the investigation. The diameter of the brachial artery was measured from the anterior to posterior interface between the media and adventitia (" $m$ " line) at the end of diastole, which was defined by the $\mathrm{R}$ wave on a continuously recorded electrocardiogram. The vessel diameter was 
Table 2 Osteocalcin, Brachial Arterial Flow-Mediated Vasodilatation, and Lumbar Spine BMD of the Normal BMD, Osteopenia, and Osteoporosis Groups (Analysis of Covariance, Adjusted for Age and Years Since Menopause)

\begin{tabular}{lccc}
\hline \hline & Normal BMD & Osteopenia & Osteoporosis \\
\hline Osteocalcin $(\mathrm{ng} / \mathrm{ml})$ & $7.7 \pm 2.5$ & $8.1 \pm 2.5$ & $9.5 \pm 2.7^{*}$ \\
Flow-mediated vasodilatation (\%) & $9.6 \pm 4.4$ & $7.9 \pm 4.4$ & $5.8 \pm 4.7^{*}$ \\
$B M D\left(\mathrm{~g} / \mathrm{cm}^{2}\right)$ & $1.04 \pm 0.06$ & $0.84 \pm 0.06^{* *}$ & $0.64 \pm 0.07^{* *, \dagger}$ \\
\hline
\end{tabular}

Abbreviation see in Table 1.

All the results are presented as means $\pm S D$.

${ }^{*} p<0.05,{ }^{* *} p<0.01$ vs normal $B M D,{ }^{\dagger} p<0.01$ vs osteopenia.

Table 3 Correlations of Brachial Arterial Flow-Mediated Vasodilatation With Clinical Variables by Pearson's

Correlation

\begin{tabular}{lcc}
\hline \hline & $r$ & $p$ value \\
\hline Age & -0.04 & 0.74 \\
Years since menopause & -0.02 & 0.87 \\
Body mass index & -0.15 & 0.17 \\
Follicle-stimulating hormone & 0.12 & 0.28 \\
Estradiol & 0.02 & 0.85 \\
Systolic blood pressure & 0.03 & 0.81 \\
Diastolic blood pressure & -0.02 & 0.83 \\
Heart rate & 0.13 & 0.22 \\
Total cholesterol & 0.05 & 0.65 \\
HDL-cholesterol & 0.06 & 0.57 \\
Triglyceride & -0.19 & 0.08 \\
LDL-cholesterol & 0.09 & 0.44 \\
Fasting plasma glucose & 0.02 & 0.84 \\
Osteocalcin & -0.08 & 0.48 \\
Lumbar spine BMD & 0.31 & $<0.01$ \\
\hline
\end{tabular}

Abbreviations see in Table 1.

measured over 4 cardiac cycles and the measurements were averaged, without previous knowledge of the subject's treatment group. Flow-mediated vasodilatation (FMD) was calculated as the percent increase in arterial diameter during hyperemia, and represents an index of endothelium-dependent vasodilatation. The percent dilatation induced by nitroglycerin, which represents an index of endotheliumindependent vasodilatation, was also calculated in a similar manner. The inter- and intra-observer variabilities for the repeated measurements of the arterial diameter at rest were $0.06 \pm 0.03$ and $0.04 \pm 0.03 \mathrm{~mm}$, respectively. The variability of FMD determined on 2 separate days was $2.7 \pm 1.2 \%$.

\section{Assays}

Blood samples were drawn from the antecubital vein in the morning after the subject had fasted for $12 \mathrm{~h}$. The subjects were allowed to rest in the supine position for at least $10 \mathrm{~min}$ prior to the sample collection. The fasting blood samples were centrifuged at $4^{\circ} \mathrm{C}$ for $15 \mathrm{~min}$ at $3,000 \mathrm{G}$, within $1 \mathrm{~h}$ of collection. The serum concentrations of FSH and estradiol were measured by radioimmunoassay. The serum total cholesterol, high-density lipoprotein-cholesterol, triglyceride, creatinine, calcium, and phosphorus concentrations were determined by using standard laboratory techniques (Medca Japan, Konosu, Japan). The concentrations of low-density lipoprotein-cholesterol were calculated using the Friedwald formula. Plasma glucose was measured in duplicate with an automatic analyzer by the glucose oxidase method (Medca Japan, Konosu, Japan). The serum osteocalcin was measured by using the immunoradiometric assay. The intra- and inter-assay coefficients of variation were $<7 \%$ for $\mathrm{FSH}$, and $<5 \%$ for estradiol, $<6 \%$ for lipids,

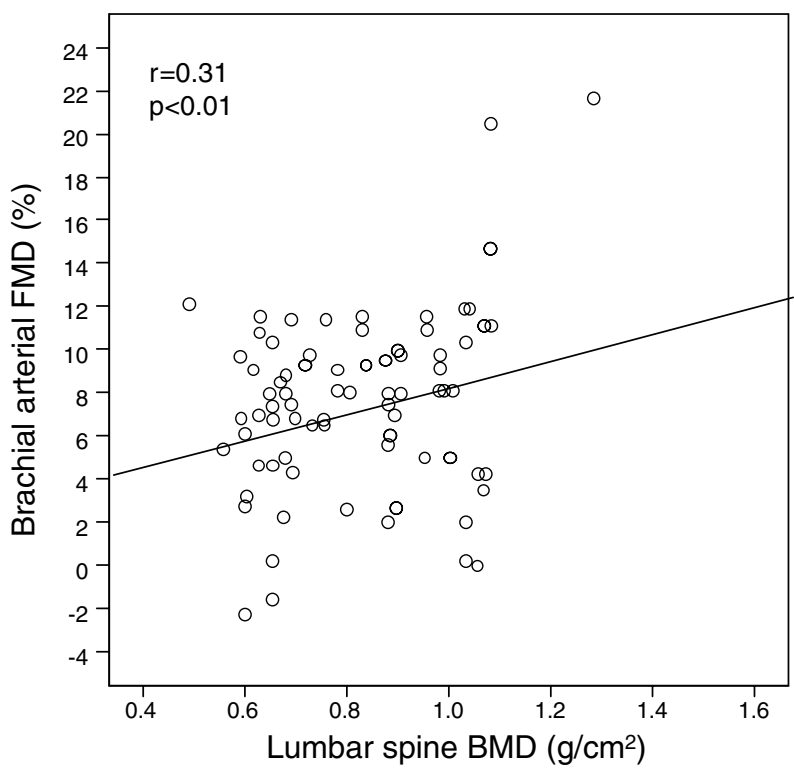

Fig 1. Correlation between brachial arterial flow-mediated vasodilatation (FMD) and lumbar spine bone mineral density (BMD) in postmenopausal women.

$<7 \%$ for plasma glucose, and $<8 \%$ for osteocalcin.

\section{Statistical Analysis}

Data are expressed as mean \pm SD. One-way analysis of variance (ANOVA) was used to compare the clinical characteristics among the 3 groups. The laboratory data for the 3 groups were compared by using analysis of covariance (ANCOVA), after adjusting for age, body mass index, and years since menopause. Pearson's correlation coefficient analyses were used to examine the relationships between the values of FMD and the values of BMD and other clinical variables. Furthermore, multiple regression analysis was performed among the values of FMD and the values of BMD and other clinical variables. All the probability values were 2 -tailed. The $p$ values $<0.05$ were considered to denote statistical significance. All statistical analyses were performed using the SPSS software (v11.0, Michigan, IL, USA).

\section{Results}

Age was significantly greater in the osteoporosis group than in the normal BMD $(\mathrm{p}<0.01)$ and osteopenia groups $(\mathrm{p}<0.01)$. Years since menopause, osteocalcin concentrations, and FMD in the osteoporotic group were also significantly greater than those in the normal BMD group $(\mathrm{p}<0.01, \mathrm{p}<0.01$, and $\mathrm{p}<0.05$, respectively). No significant 
Table 4 Independent Predictors of Brachial Arterial Flow-Mediated Vasodilatation With Clinical Variables by Multiple Regression Analysis

\begin{tabular}{lrc}
\hline \hline & $\beta$ & $p$ value \\
\hline Age & -0.12 & 0.83 \\
Years since menopause & 0.25 & 0.64 \\
Body mass index & -0.22 & 0.09 \\
Follicle-stimulating hormone & 0.10 & 0.44 \\
Estradiol & 0.03 & 0.83 \\
Systolic blood pressure & -0.18 & 0.39 \\
Diastolic blood pressure & 0.12 & 0.54 \\
Total cholesterol & 0.08 & 0.48 \\
HDL-cholesterol & -0.10 & 0.44 \\
Triglyceride & -0.19 & 0.17 \\
LDL-cholesterol & 0.07 & 0.57 \\
Fasting plasma glucose & -0.01 & 0.93 \\
Osteocalcin & 0.03 & 0.83 \\
Lumbar spine BMD & 0.40 & $<0.01$ \\
\hline
\end{tabular}

Abbreviations see in Table 1.

differences in nitroglycerin-induced vasodilatation were seen among the 3 groups. BMD was significantly lower in the osteoporosis group than in the osteoporosis or normal BMD group ( $\mathrm{p}<0.01$ for both) and in the osteopenia group than in the normal BMD group $(\mathrm{p}<0.01)$. However, there were no significant differences in other characteristics among the 3 groups (Table 1 ).

After adjusting for age and years since menopause, serum osteocalcin concentrations were found to be significantly higher in the osteoporosis group than in the normal BMD group $(9.5 \pm 2.7$ vs $7.7 \pm 2.5 \mathrm{ng} / \mathrm{ml} ; \mathrm{p}<0.05)$. Women with osteoporosis were found to show significantly lower FMD than those with normal BMD $(5.8 \pm 4.7$ vs $9.6 \pm 4.4 \%$; $\mathrm{p}<0.05$ ). Furthermore, the BMD was significantly lower in the osteoporosis group than in the osteoporosis or normal BMD group $(p<0.01$ for both) and also in the osteopenia group than in the normal BMD group ( $\mathrm{p}<0.01$; Table 2$)$.

The results of the univariate regression analysis revealed that brachial arterial FMD was significantly positively correlated with BMD $(r=0.34, p<0.01)$, but showed no significant association with other clinical variables (Table 3, Fig 1). In addition, multivariate regression analysis revealed that the FMD was significantly positively correlated with BMD $(\mathrm{p}<0.01)$, but showed no significant association with other clinical variables (Table4).

\section{Discussion}

The present study showed that brachial arterial FMD was more impaired in postmenopausal women with osteoporosis than in those with normal bone mass. Brachial arterial FMD was significantly positively associated with lumbar spine BMD.

The association between brachial arterial endothelial function and lumbar spine BMD has been shown in a few studies. Sanada et al reported that postmenopausal women with a lower lumbar spine BMD, as measured by DXA, have impaired forearm endothelial function as measured by strain-gauge plethysmography 5 The present study also revealed that postmenopausal women with low lumbar spine BMD, as measured by DXA, have impaired brachial arterial endothelial function as measured by FMD. Although there were differences in the methods used to assess the brachial arterial endothelial function between the aforementioned study and the present study, the findings of the
2 studies were consistent. In addition, the present study found a positive association of brachial arterial FMD with lumbar spine BMD in postmenopausal women. In our previous study 15 brachial-ankle pulse wave velocity, which has being regarded as a marker reflecting vascular damage, ${ }^{16}$ was significantly negatively correlated with lumbar spine BMD in postmenopausal women. This study supports the results of the present study. Accordingly, it is likely that postmenopausal women with osteoporosis might have more impaired brachial arterial endothelial function than postmenopausal women with normal bone mass.

The nature of the association between brachial arterial endothelial function and BMD is not yet clearly understood. However, we can speculate on several possible explanations. Epidemiological data have suggested that estrogen deficiency is a risk factor for cardiovascular disease and osteoporosis 17,18 Bone and arteries are target organs for estrogen actions. Estrogen receptors have been demonstrated on osteoblasts ${ }^{19}$ osteoclasts ${ }^{20}$ and vascular endothelial and smooth muscle cells ${ }^{21}$ suggesting that there are direct effects of estrogen on vascular endothelial cells and bone cells. Hormone replacement therapy in postmenopausal women improves brachial arterial endothelial function ${ }^{12}$ and increases BMD?2 Estrogen might be one of the important factors explaining the relationship between brachial arterial endothelial function and bone mass. However, in the present study, the serum estradiol levels showed no relation to brachial arterial FMD or lumbar spine BMD; these results might be reflected by a small group of early postmenopausal women.

There are other possible explanations for the present study findings. NO is a free radical involved in vascular relaxation ${ }^{23}$ In humans, dilatation of conduit arteries in response to reactive hyperemia is reduced by inhibitors of NO synthesis, suggesting an important role for NO in FMD 24 Impairment of NO production might cause a fall in radial blood flow in healthy volunteers ${ }^{4} 4$ In dogs, bone blood flow facilitates bone formation and mineralization.25 Because the decreased NO might cause bone loss, NO might play an important role in the pathogenesis of both endothelial dysfunction and osteoporosis. In addition, osteocalcin, known as bone Gla protein, has been used as a marker of high bone turnover because it is the most abundant non-collagenous protein found in bone and it is produced by osteoblasts in the course of bone remodeling? ${ }^{26} \mathrm{In}$ patients with severe atherosclelosis, circulating osteocalcin levels were increased ${ }^{27}$ Another study showed that during atherogenesis, osteocalcin had a regulatory role not only in atherosclerotic calcium but also in osteoclastogenesis ${ }^{28}$ Although osteocalcin might be one of the important factors explaining the relationship between endothelial function and bone mass, the present study found that brachial arterial FMD showed no significant association with osteocalcin concentrations. Moreover, secondary hyperparathyroidism, which can be induced by vitamin D deficiency in the elderly, is known to be associated with soft-tissue calcium deposition as well as bone loss.9 ${ }^{2}$ Oxidized lipids also promote atherogenesis ${ }^{30}$ and inhibit differentiation and mineralization of bone cells 31 Several bone-associated proteins, including osteopontin and osteoprotegerin, have been reported to be expressed in atherosclerotic lesions $32,33 \mathrm{Un}$ fortunately, we had no data about these factors in our study subjects.

In conclusion, postmenopausal women with osteoporosis might have impaired brachial arterial endothelial function, 
suggesting that brachial arterial endothelial function might be associated with lumbar spine bone mass in postmenopausal women. The number of subjects in the present study was low and many other risk factors for atherosclerosis and osteoporosis were not measured. Further study is needed to explore the relationship between brachial arterial endothelial function and bone mass in postmenopausal women.

\section{Acknowledgments}

We are grateful to Naoaki Tsunoda, Hiroyuki Takada, Hiromitsu Takahashi and Hiroe Hagiwara for their technical assistance, and we thank Kazuo Sakaguchi, Miki Shirouzu, Tomoko Sakurai, Mina Aoki, Yuko Masuda, Kanae Kodaira, Setsuko Kobayashi and Masumi Tanimoto for their assistance with the clinical coordination.

\section{References}

1. von der Recke P, Hansen MA, Hassager C. The association between low bone mass at the menopause and cardiovascular mortality. Am J Med 1999; 106: $273-278$.

2. Mosca L, Manson JE, Sutherland SE, Langer RD, Barrett-Connor E. Cardiovascular disease in women: A statement for healthcare professionals from the American Heart Association Writing Group. Circulation 1997; 96: $2468-2482$.

3. Barengolts EI, Berman M, Kukreja SC, Kouznetsova T, Lin C, Chomka EV. Osteoporosis and coronary atherosclerosis in asymptomatic postmenopausal women. Calcif Tissue Int 1998; 62: 209-213.

4. Hak AE, Pols HA, van Hemert AM, Hofman A, Witteman JC. Progression of aortic calcification is associated with metacarpal bone loss during menopause: A population-based longitudinal study. Arterioscler Thromb Vasc Biol 2000; 20: 1926-1931.

5. Sanada M, Taguchi A, Higashi Y, Tsuda M, Kodama I, Yoshizumi $\mathrm{M}$, et al. Forearm endothelial function and bone mineral loss in postmenopausal women. Atherosclerosis 2004; 176: 387-392.

6. Hirose K, Tomiyama H, Okazaki R, Arai T, Koji Y, Zaydun G, et al. Increased pulse wave velocity associated with reduced calcaneal quantitative osteo-sono index: Possible relationship between atherosclerosis and osteopenia. J Clin Endocrinol Metab 2003; 88: $2573-$ 2578 .

7. Uyama O, Yoshimoto Y, Yamamoto Y, Kawai A. Bone changes and carotid atherosclerosis in postmenopausal women. Stroke 1997; 28: $1730-1732$

8. Vane JR, Anggard EE, Botting RM. Regulatory functions of the vascular endothelium. $N$ Engl J Med 1990; 323: 27-36.

9. Anggard E. Nitric oxide: Mediator, murderer, and medicine. Lancet 1994; 343: 1199-1206.

10. Kanis JA, Melton III LJ, Christiansen C, Johnston CC, Khaltaev N. The diagnosis of osteoporosis. J Bone Miner Res 1994; 9: 1137 1141.

11. Gotoh M, Mizuno K, Ono Y, Takahashi M. High blood pressure, bone-mineral loss and insulin resistance in women. Hypertens Res 2005; 28: $565-570$.

12. Sumino H, Ichikawa S, Ohyama Y, Takahashi T, Saito Y, Nakamura $\mathrm{T}$, et al. Effect of transdermal hormone replacement therapy on the monocyte chemoattractant protein- 1 concentrations and other vascular inflammatory markers and on endothelial function in postmenopausal women. Am J Cardiol 2005; 96: 148-153.

13. Ohike Y, Kozaki K, Iijima K, Eto M, Kojima T, Ohga E, et al Amelioration of vascular endothelial dysfunction in obstructive sleep apnea syndrome by nasal continuous positive airway pressure: Possible involvement of nitric oxide and asymmetric NG, NG-dimethylarginine. Circ J 2005; 69: 221-226.
14. Tanriverdi H, Evrengul H, Tanriverdi S, Turgut S, Akdag B, Kaftan $\mathrm{HA}$, et al. Improved endothelium dependent vasodilation in endurance athletes and its relation with ACE I/D polymorphism. Circ J 2005; 69: 1105-1110.

15. Sumino H, Ichikawa S, Kasama S, Takahashi T, Kumakura H, Takayama Y, et al. Elevated arterial stiffness in postmenopausal women with osteoporosis. Maturitas 2006; 55: 212-218.

16. Cohn JN. Vascular wall function as a risk marker for cardiovascular disease. J Hypertens 1999; 17(Suppl 5): S41-S44.

17. Kalin MF, Zumoff B. Sex hormones and coronary disease: A review of the clinical studies. Steroids 1990; 55: 330-352.

18. Bauer DC, Browner WS, Cauley JA, Orwoll ES, Scott JC, Black DM, et al. Factors associated with appendicular bone mass in older women: The Study of Osteoporotic Fractures Research Group. Ann Intern Med 1993; 118: 657-665.

19. Eriksen EF, Colvard DS, Berg NJ, Graham ML, Mann KG, Spelsberg $\mathrm{TC}$, et al. Evidence of estrogen receptors in normal human osteoblastlike cells. Science 1988; 241: 84-86.

20. Oursler M, Peterson L, Fitzpatrick I, Riggs BL, Spelsberg TC. Human giant cell tumors of the bone (osteoclastomas) are estrogen target cells. Proc Natl Acad Sci USA 1994; 91: 5227-5231.

21. Mendelsohn ME, Karas RH. The protective effects of estrogen on the cardiovascular system. $N$ Engl J Med 1999; 340: 1801 - 1811.

22. Felson DT, Zhang Y, Hannan MT, Kiel DP, Wilson PW, Anderson JJ. The effect of postmenopausal estrogen therapy on bone density in elderly women. N Engl J Med 1993; 329: 1141-1146.

23. Palmer RM, Ferrige AG, Moncada S. Nitric oxide release accounts for the biological activity of endothelium-derived relaxing factor. Nature 1987; 327: 524-526.

24. Joannides R, Haefeli WE, Linder L, Richard V, Bakkali EH, Thuillez $\mathrm{C}$, et al. Nitric oxide is responsible for flow-dependent dilatation of human peripheral conduit arteries in vivo. Circulation 1995; 91: $1314-1319$

25. Kelly PJ, Montgomery RJ, Bronk JT. Reaction of the circulatory system to injury and regeneration. Clin Orthop Relat Res 1990; 254: 275-288.

26. Hauschka PV, Lian JB, Cole DEC, Gundeberg CM. Osteocalcin and matrix Gla protein: Vitamin K-dependent proteins in bone. Physiol Rev 1989; 69: 990-1047.

27. Braam LA, Dissel P, Gijsbers BL, Spronk HM, Hamulyak K, Soute BA, et al. Assay for human matrix Gla protein in serum: Potential applications in the cardiovascular field. Arterioscler Thromb Vasc Biol 2000; 20: 1257-1261.

28. Dhore CR, Cleutjens JP, Lutgens E, Cleutjens KB, Geusens PP, Kitslaar PJ, et al. Differential expression of bone matrix regulatory proteins in human atherosclerotic plaques. Arterioscler Thromb Vasc Biol 2001; 21: 1998-2003.

29. Stefenelli T, Mayr H, Bergler-Klein J, Globits S, Woloszczuk W, Niederle B. Primary hyperparathyroidism: Incidence of cardiac abnormalities and partial reversibility after successful parathyroidectomy. Am J Med 1993; 95: 197-202.

30. Witztum JL, Steinberg D. Role of oxidized low density lipoprotein in atherogenesis. J Clin Invest 1991; 88: 1785-1792.

31. Parhami F, Morrow AD, Balucan J, Leitinger N, Watson AD, Tintut $\mathrm{Y}$, et al. Lipid oxidation products have opposite effects on calcifying vascular cell and bone cell differentiation: A possible explanation for the paradox of arterial calcification in osteoporotic patients. Arterioscler Thromb Vasc Biol 1997; 17: 680-687.

32. Giachelli CM, Bae N, Almeida M, Denhardt DT, Alpers CE, Schwartz SM. Osteopontin is elevated during neointima formation in rat arteries and is a novel component of human atherosclerotic plaques. J Clin Invest 1993; 92: 1686-1696.

33. Jono S, Ikari Y, Shioi A, Mori K, Miki T, Hara K, et al. Serum osteoprotegerin levels are associated with the presence and severity of coronary artery disease. Circulation 2002; 106: 1192-1194. 